\title{
Effect of exercise on lung-perfusion scanning in patients with bronchogenic carcinoma
}

\author{
B. Chenuel*, P. Haouzi*, P. Olivier", P.Y. Marie* , B. Chalon*, J. Borrelly
}

Effect of exercise on lung-perfusion scanning in patients with bronchogenic carcinoma. B. Chenuel, P. Haouzi, P. Olivier, P. Y. Marie, B. Chalon, J. Borrelly. (C) ERS Journals Ltd 2002

ABSTRACT: The aim of this study was to determine whether perfusion-scintillation scanning, used as a predictive pre-operative index of lung functionality in patients with lung cancer, is affected by the level of pulmonary blood flow (PBF).

Twenty patients with primary lung cancer underwent spirometry and a radionuclideperfusion scan (macroaggregated albumin particles labelled with ${ }^{99 \mathrm{~m}}$ Technetium) both at rest and during the last minute of a ramp-like increase in work rate until exhaustion.

On average, the perfusion of the lung with the tumour was significantly reduced by the same magnitude at rest and during exercise (mean \pm SD: $-9 \pm 6 \%$ versus $-10 \pm 4 \%$ of the cardiac output), regardless of the extent of the tumour. However, subject-by-subject analysis revealed that in two patients, a larger decrease in the perfusion of the lung with the tumour was observed during exercise than at rest $(-11 \%$ and $-17 \%$, respectively). This leads to an underestimation of predictive postoperative functional parameters if resting values are used in these patients.

The use of perfusion scintigraphy at rest therefore gives a clear picture of the functionality of the lung before resection in most patients requiring surgery. Eur Respir J 2002; 20: 710-716.
*Service d'Exploration Fonctionnelle Respiratoire et Laboratoire de Physiologie, Faculté de Médecine de Nancy, Nancy, " Service de Médecine Nucléaire, Service de Chirurgie Thoracique, Centre Hospitalier Universitaire (CHU) de Nancy-Brabois, Nancy, France.

Correspondence: P. Haouzi, Laboratoire de Physiologie, Faculté de Médecine de Nancy, Avenue de la Forêt de Haye, B.P. 184, 54505 Vandoeuvre-lèsNancy Cedex, France.

Fax: 33383683739

E-mail: p.haouzi@chu-nancy.fr

Keywords: Exercise, lung cancer, pneumonectomy, preoperative perfusion-lung scanning, pulmonary function tests

Received: June 252001

Accepted after revision: May 82002
Various strategies have been proposed to identify patients, prior to a pulmonary resection, who may not be able to tolerate the consequences of a reduction in lung tissue [1]. Lung function tests, such as determination of forced expiratory volume in one second (FEV1), vital capacity, airway or pulmonary vascular resistances, carbon monoxide diffusing capacity of the lung $(D \mathrm{~L}, \mathrm{CO})$ and resting arterial blood gas, are not always sufficient to define precisely the "functional operability" of a patient [1-6]. In other words, except for very deteriorated or normal lung function, standard tests are not sensitive enough to differentiate between patients who could support a limited resection or a pneumonectomy [4-6]. Such a prediction would require evaluation of the functionality of the tissue being removed since the effects of the resection would be different if the removed portion of the lung had a normal, a lower or a greater than normal contribution to the total pulmonary gas exchange.

Evaluation of the distribution of cardiac output between the right and left lungs, or within a lung, using perfusion-scintillation scanning has been proposed [7-10]. This method assumes that the perfusion of a given region of a lung is proportional to its level of gas exchange $[9,10]$. Reduced perfusion of a portion of the lung, which is typical in lung cancer, is considered to be a marker of nonfunctionality, and thus few or no consequences are to be expected after pulmonary resection [11]. This approach is currently used to estimate postoperative FEV1 (FEV1,ppo) as the product of preoperative FEV1 to the fraction of pulmonary blood flow perfusing the expected remaining lung $[1,10,11]$. However, this approach does not necessarily give a clear idea of the immediate and long-term tolerance following lung resection. It has even been suggested that patients who were denied lung resection on the basis of low predicted FEV1, may well have tolerated the consequences of a thoracotomy, if different criteria, such as the level of exercise performance, were chosen [2, 12-15]. Indeed, in normal life, pulmonary blood flow and gas exchange must adapt continuously to the metabolic rate, and this capacity, or lack of capacity, of adaptation cannot be routinely evaluated. For instance, the contribution of a portion of a lung to the total gas exchange can be underestimated if the pulmonary circulation is redistributed towards healthy parts of the lungs when pulmonary blood flow (oxygen $\left(\mathrm{O}_{2}\right)$ uptake) rises, as during a physical task. Indeed, the possible impact of the level of cardiac output on blood-flow distribution in patients with lung cancer, related to emotional stress, pain or anxiety during macroaggregated albumin particles injection, has never been examined and is thus not currently monitored and taken into account as a possible cause of variability.

The aim of this study was therefore to compare the distribution of pulmonary perfusion between the lungs 
at rest and during a maximal exercise in patients with bronchogenic carcinoma. It was questioned whether resting scanning gives a reasonable approximation of the distribution of pulmonary blood flow, even when an increase in pulmonary gas exchange is needed. Such a question may have relevant implications for the strategy routinely used to evaluate lung-resection candidates.

\section{Method}

\section{Patient population}

Twenty patients (six females, 14 males) with primary lung cancer were studied. They were briefed as to the general purpose of the study and informed consent was obtained. This study was approved by the local ethics committee. The mean (range) age of the patients was 65 yrs (54-77 yrs), their height was $1.66 \mathrm{~m}(1.48-1.84 \mathrm{~m})$ and their weight was $68 \mathrm{~kg}$ $(54-86 \mathrm{~kg})$. The tumour was located in the right lung in 13 patients.

\section{Material and methods}

The patients exercised sitting on an electromagnetically-braked hyperbolic cycle-ergometer (Lode Excalibur, Gronigen, the Netherlands) and breathed room air through a mouthpiece connected to a two-way valve (Jaeger, Hoechberg, Germany), as previously described [16]. Briefly, expiratory flow was measured by a heated pneumotachograph (Fleisch pneumotachograph no. 3; Medical Graphic, MN, USA). A small aliquot of gas was continuously drawn from the mouthpiece for determination of $\mathrm{O}_{2}$ and carbon dioxide $\left(\mathrm{CO}_{2}\right)$ concentrations (Datex Analysers; Medical Graphics System, Medical graphics Corporation, St Paul, MN, USA). The electrocardiogram was monitored from a three-lead configuration and a cardiotachometer was used to determine the cardiac frequency from the R-R interval. Expiratory flow, the partial pressures of $\mathrm{O}_{2}\left(\mathrm{PO}_{2}\right)$ and $\mathrm{CO}_{2}\left(\mathrm{PCO}_{2}\right)$ were digitised for the breath-by-breath calculation of pulmonary gas exchange. Transcutaneous $\mathrm{O}_{2}$ saturation was monitored throughout the exercise test (Nellcor Pulse Oximeter; Nellcor Incorporated, Pleasanton, CA, USA).

The lung volumes and forced expiratory parameters were determined by Autospiro AS-600 (Minato Medical, Osaka, Japan).

The distribution of pulmonary blood flow between the lungs was estimated by perfusion-lung scan. Macroaggregated albumin particles with a diameter of $30-50 \mu \mathrm{m}$ (Pulmocis $\mathbb{R}$, CIS bio international, Gif sur Yvette, France), labelled with ${ }^{99 \mathrm{~m}}$ Technetium, were injected intravenously. Following the injection, a scintigraphical acquisition was performed in a posterior view using a gamma camera (DSX gamma camera; SMVI, Buc, France) equipped with an all-purpose collimator. The scintigraphical images were acquired from patients laying in the supine position, in planar mode, with a preset count of 400 kilo counts (Kcts) and a $64 \times 64$ matrix. A DST processing computer (SVMI) was used for data processing. Rectangular regions of interest (ROI) were drawn for the right and the left lung.

\section{Protocol}

A progressively increasing work-rate (WR) test (ramp pattern) was performed by each subject. The WR was increased every minute by $10 \mathrm{~W}$ until exhaustion occurred. The maximal level of WR that could be sustained for 1 min was considered to be the maximal WR and the corresponding oxygen uptake $\left(V^{\prime} \mathrm{O}_{2}\right)$ as peak $V^{\prime} \mathrm{O}_{2}$. An intial injection of albumin particles was administered during the last minute of exercise, followed $10 \mathrm{~min}$ later by an initial acquisition. The patients were requested to indicate by means of a sign when they felt exhausted and the injection was administered immediately after, with the subjects required to continue pedalling for a few additional seconds. Sixty minutes after the first acquisition, the patient received a second injection of albumin particles in the resting position. The injected activity was five-times lower during exercise (74 megabecquerel $(\mathrm{MBq}))$ than at rest $(370 \mathrm{MBq})$. To avoid any possible influence of gravity on albumin particle distribution between the two conditions, each patient was injected in the sitting position both at rest and while exercising.

Finally, surgical-pathological tumour, node, metastasis staging (pTNM) was established pre- and postoperatively, and each patient was then staged according to the international classification system [17]. The redistribution of pulmonary blood flow both at rest and during exercise was evaluated according to this classification.

\section{Data analysis}

The predicted normal FEV1 values (FEV1,pred), based on age, sex and height, were those from the European Community for Coal and Steel [18]. FEV1 were expressed in per cent of these predicted normal values.

Activity in each ROI was expressed in counts by ROI. The perfusion of the lung with the tumoural process was expressed as the percentage of total lung activity during exercise. The same analysis was applied to the resting acquisition after subtraction of the residual activity from the first injection, and correction for the delay in acquisition time. The same ROI were used for both acquisitions. Fifty-five per cent of the total pulmonary blood flow (PBF) was assumed to be the portion of the cardiac output diverted towards the right lung. The perfusion of the lung with the tumour was expressed in per cent of the total pulmonary perfusion or as the difference between the observed and expected value.

The effect of muscular exercise on the distribution of the total PBF was assessed by comparing the relative perfusion of the lung with the tumour at rest and at the end of the ramp-like exercise using a paired 
t-test. The difference in perfusion between rest and exercise was compared according to stage (analysis of variance (ANOVA)). A p-value of $<0.05$ was considered to be significant.

\section{Results}

\section{Resting parameters}

As a group, the patients had a significant reduction in the FEV1 $(76.4 \pm 18.9 \%$ pred normal values, range $43-113 \%$ ). In 11 patients, FEV1 was $<75 \%$ pred. The perfusion of the lung with the tumour was significantly reduced. Two examples are shown in figure 1 .
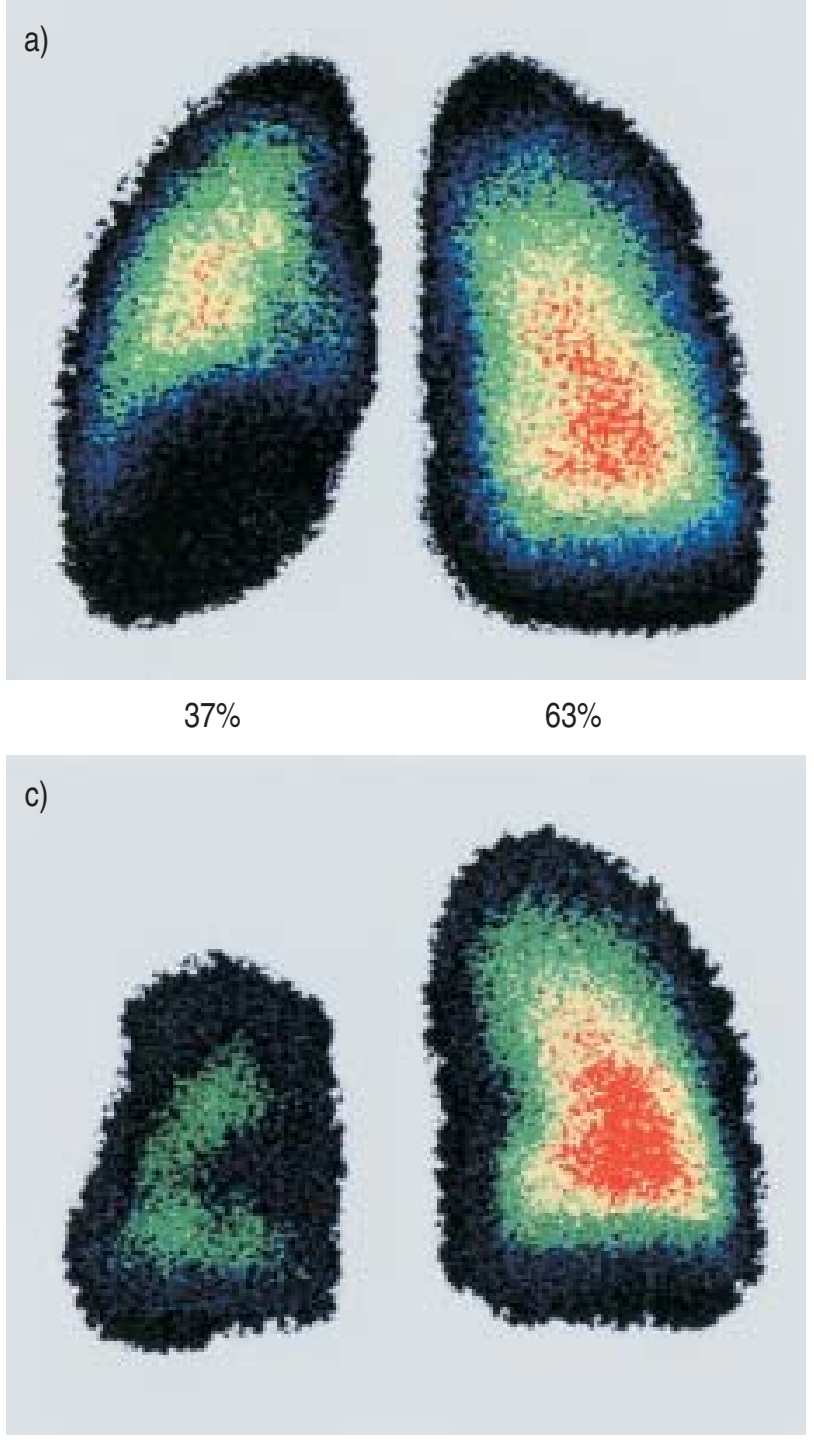

$28 \%$

$72 \%$
On average, $8.5 \pm 6 \%$ of the total cardiac output was diverted away from the lung with the tumour (fig. 2). More specifically, the right lungs received only $46.1 \pm 6.7 \%$ of the total PBF with a cancer, whereas only $37.1 \pm 5.0 \%$ of the cardiac output reached the left lungs with a tumour.

\section{Exercise}

The maximal level of exercise that could be sustained by the subjects was reduced, reflecting their low level of fitness. On average, the maximal WR that could be tolerated was $76 \pm 30 \mathrm{~W}$ $\left(V^{\prime} \mathrm{O}_{2}=982 \pm 290 \mathrm{~mL} \cdot \mathrm{min}^{-1}\right.$, respiratory exchange ratio $(\mathrm{R})=1.12 \pm 0.09)$. Although each patient exercised until
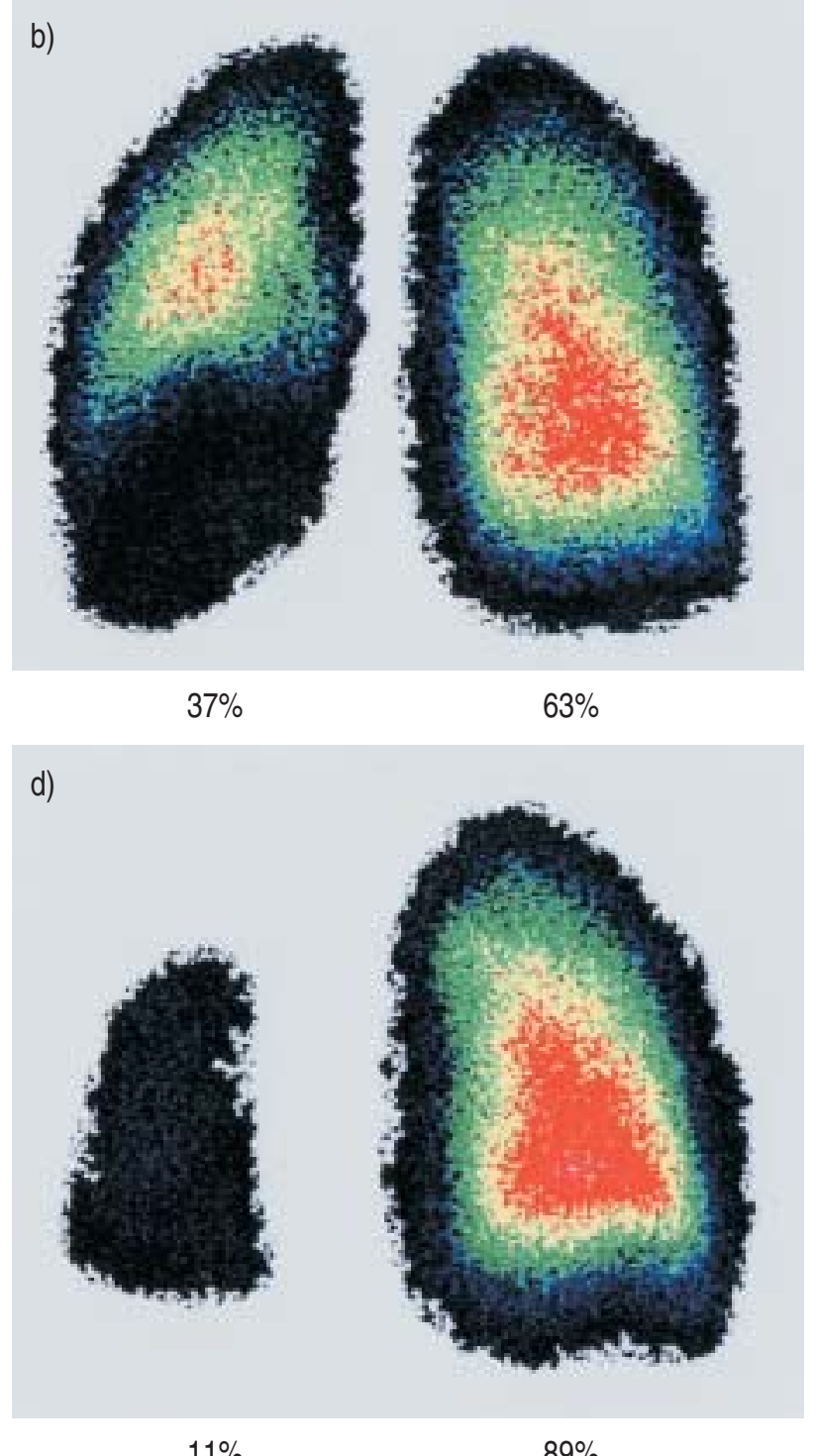

$11 \%$

Fig. 1.-Example of perfusion-lung scanning following an intravenous injection of macroaggregated albumin particles labelled with ${ }^{99 m}$ Technetium in two different patients (posterior view) at rest ( $a$ and c) and at the end of exercise (b and d). Note that the perfusion of the lung with the tumour was reduced in both patients. As was the case in most of the patients, in patient A ( $a$ and b), this distribution was not markedly affected by the level of pulmonary gas exchange and blood flow. In patient B (c and d), a redistribution of pulmonary blood flow towards the healthy lung was provoked by exercise. This type of response was only observed in two patients. 

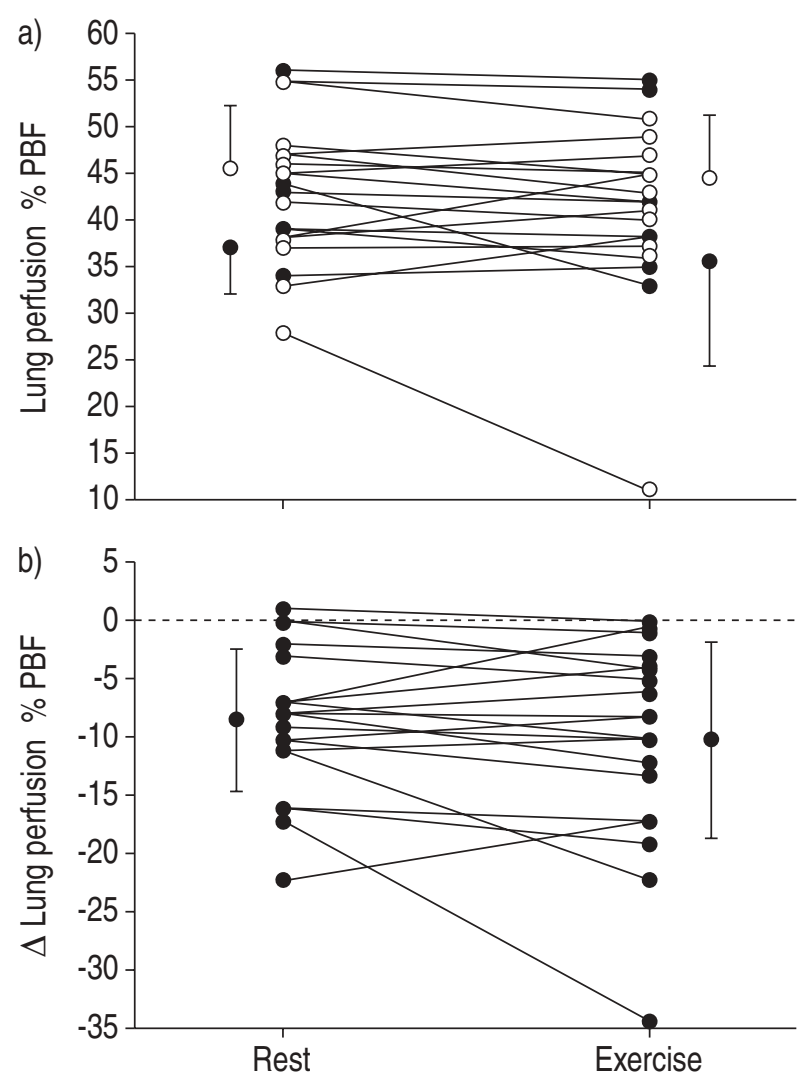

Fig. 2.-Perfusion of the lung with the tumour at rest and during exercise in all the patients expressed in per cent of a) the total pulmonary blood flow $(\mathrm{PBF})$ and $\mathrm{b})$ in variation of the expected per cent of PBF (assuming that the right lung receives $55 \%$ of the total perfusion). In a) the mean and $\mathrm{SD}$ of the perfusion are shown separately for the patients with a tumour located in the right (open symbols) or the left lung (closed symbols).

exhaustion, most of them stopped before reaching their maximal cardiac frequency $(80 \pm 11.5 \%$ of the maximal predicted cardiac-frequency response). The maximal level of ventilation was, in all but two of the subjects, lower than their predicted maximal ventilatory capacity $(65.5 \pm 26.4 \%$ of the predicted maximal ventilatory capacity, defined as FEV1×35). Finally, in four patients, a decrease in transcutaneous $\mathrm{O}_{2}$ saturation was observed but always remained $>92 \%$. Albumin-particle injection at the end of the ramp test revealed that, as at rest, there was a redistribution of the total pulmonary blood flow towards the healthy lung. An example is shown in figure 1. Indeed, $10.1 \pm 8.4 \%$ of the total $\mathrm{PBF}$ was diverted from the lung with the tumour (fig. 2). However, as a group there was no significant difference in the relative perfusion of the lungs between rest and exercise (fig. 2). Although, there was a relative reduction in the distribution of PBF to the lung with the tumour during exercise, it is worth noting that, assuming proportionality between pulmonary gas exchange and pulmonary perfusion [19], the lung with the tumour was still responsible for an $\mathrm{O}_{2}$ uptake that averaged $418.7 \pm 114.1 \mathrm{~mL} \cdot \mathrm{min}^{-1}$.

Subject-by-subject analysis showed that in six subjects there was either no change or only a slight increase in the relative perfusion of the lung with the tumour during exercise, compared to the values at rest $(0-7 \%$ of $\mathrm{PBF})$. In the remaining 14 subjects, the perfusion of the lung with the tumour was relatively, but again not significantly, reduced by exercise (-4-34\% of PBF). Nevertheless, all but two subjects had a variation in one or the other direction that represented $\leqslant 7 \%$ of the total PBF (fig. 3). In two subjects, exercise induced a larger drop in the relative perfusion of the lung with the tumour than at rest, which represented $11 \%$ and $17 \%$ of the total pulmonary blood. There was no correlation between the level of WR and the deterioration of FEV1 or the degree of hypoperfusion of the lung with the tumour.

\section{International staging classification and blood-flow redistribution}

Two of the 20 patients did not undergo a surgical procedure due to a general poor condition. The postoperative staging of the remaining 18 patients is shown in table 1 , together with the perfusion data at rest and during exercise. It is worth noting that six patients were understaged pre-operatively. More specifically, three patients (nos. 3, 4, 6) who were staged I or II prior to surgery had a mediastinal or diaphragmatic pleural invasion that was discovered on the removed lobe. Therefore, these patients were staged as IIIB postoperatively. In addition, three patients who were staged I and II prior to surgery either had a second tumour that was found in the removed lobe (patient no. 5) or malignant pleural effusion that was discovered pre- or postoperatively (nos. 7 and 10). These patients were staged as IIIB. All the patients were treated according to the international recommendation $[1,20,21]$.

In summary, eight patients belonged to stage I, while six patients were stage IIIA and four were stage IIIB. As a group there was no significant difference in the magnitude of blood-flow redistribution at rest or

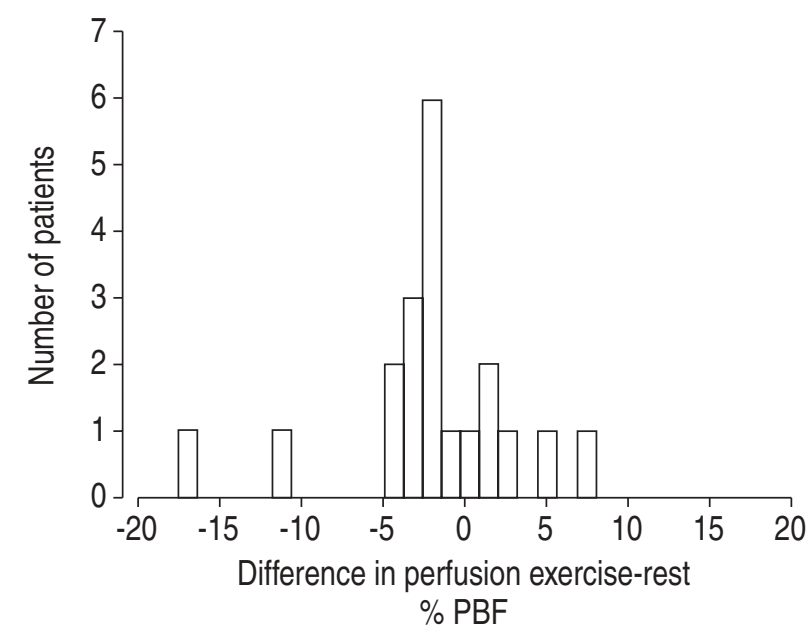

Fig. 3.-Frequency distribution of the changes in the relative perfusion of the lungs with the tumour induced by exercise. Note that the variation in perfusion was $<7 \%$ of total pulmonary perfusion for all but two subjects. PBF: pulmonary blood flow. 
Table 1.-Characteristics and outcomes of the 18 patients who underwent surgery

\begin{tabular}{|c|c|c|c|c|c|c|c|}
\hline Patients & $\begin{array}{l}\text { Age } \\
\text { yrs }\end{array}$ & Histopathology & pTNM & Stage & $\begin{array}{l}\text { FEV1 } \\
\% \text { pred }\end{array}$ & $\begin{array}{c}\Delta \text { perf } \\
\text { Rest } \% \text { PBF }\end{array}$ & $\begin{array}{c}\Delta \text { perf } \\
\text { Exercise } \% \text { PBF }\end{array}$ \\
\hline 1 & 69 & Adenocarc & T2N0M0 & I & 72,5 & -10 & -13 \\
\hline 2 & 66 & Adenocarc. & $\mathrm{T} 2 \mathrm{~N} 2 \mathrm{M} 0$ & IIIA & 57 & -7 & -10 \\
\hline $3^{*}$ & 61 & Adenocarc. & T3N1M0 & IIIA & 108 & -3 & -5 \\
\hline $4^{*}$ & 78 & Adenocarc. & T3N1M0 & IIIA & 84 & 0 & -1 \\
\hline $5^{*}$ & 69 & Adenocarc. & T4N2M0 & IIIB & 77 & 0 & -4 \\
\hline $6^{*}$ & 70 & Adenocarc. & T3N1M0 & IIIA & 113 & -2 & -3 \\
\hline $7 *$ & 57 & Adenocarc. & T4N1M0 & IIIB & 82 & -8 & -8 \\
\hline 8 & 71 & Adenocarc. & T1N0M0 & I & 75 & -7 & -4 \\
\hline 9 & 62 & Adenocarc. & T3N1M0 & IIIA & 54 & -11 & -22 \\
\hline $10^{*}$ & 58 & Adenocarc. & T4N2M0 & IIIB & 98 & -11 & -10 \\
\hline 11 & 68 & Squamous cell carc. & T2N0M0 & I & 45 & -22 & -17 \\
\hline 12 & 64 & Squamous cell carc. & T1N0M0 & I & 78 & 1 & 0 \\
\hline 13 & 76 & Squamous cell carc. & T2N0M0 & I & 81,7 & -7 & -5 \\
\hline 14 & 59 & Squamous cell carc. & T1N0M0 & I & 43 & -16 & -19 \\
\hline 15 & 68 & Squamous cell carc. & T2N0M0 & I & 80 & -8 & -12 \\
\hline 16 & 62 & Squamous cell carc. & T2N0M0 & I & 63 & -10 & -8 \\
\hline 17 & 64 & Squamous cell carc. & T4N2M0 & IIIB & 60 & -17 & -34 \\
\hline 18 & 78 & Squamous cell carc. & T3N1M0 & IIIA & 73 & -9 & -10 \\
\hline
\end{tabular}

Adenocarc.: adenocarcinoma; Squamous cell carc.: squamous cell carcinoma; pTNM: surgical-pathological staging [17]; $\Delta$ perf: perfusion of the lung with the tumour at rest and during exercise, expressed as the difference between the actual and the expected $\%$ of pulmonary blood flow ( $55 \%$ for the right lung and $45 \%$ for the left lung). *: patients who were understaged prior to surgery (see result section for details).

during exercise according to the local extent of the tumour. The change in blood-flow redistribution between rest and exercise averaged $0.33 \pm 4 \%$ of the total PBF in the T1 and T2 groups. The patients belonging to the T3 and T4 groups had a decrease in the perfusion of the lung with the tumour during exercise which averaged $-4 \pm 6 \%$ of the cardiac output (NS). Similarly, although the two patients who had the largest redistribution in $\mathrm{PBF}$ during exercise belonged to stage IIIA and IIIB, there was no statistical difference in the degree of PBF redistribution between stage I and IIIA and B.

\section{Discussion}

It was found that the presence of a bronchogenic carcinoma was associated with a redistribution of PBF towards the healthy portions of the lung that was not significantly affected by the level of pulmonary gas exchange (and pulmonary blood flow) in 18 of the 20 patients studied. Indeed, in these patients, a three-fold increase in pulmonary gas exchange had little effect, $<7 \%$ of the total cardiac output, on the distribution of PBF to the lungs. A more severe hypoperfusion of the lung with the tumour was observed in only two subjects during exercise. In such a situation, resting scanning overestimated the potential contribution of the lung with the tumour to pulmonary exchange, since any increase in cardiac output is preferentially diverted towards the other lung.

\section{Patient population}

The group of patients studied, including patients belonging to stage IIIB, had a relatively large range of extension of their tumour. Such patients, who are not typical candidates for surgery, are worth describing to assess the limit of split function for two reasons. The first is that surgery can be part of their treatment (which includes chemo- and radiotherapy). In this respect, ScHIRREN et al. [1] reported that 15\% of patients with stage IIIB had had surgery. The second reason is that some of them may have been understaged prior to the surgical procedure. For example, in a group of 1,940 patients with lung cancer, BüLzEBRUCK et al. [22] reported that only 57\% of patients had been correctly staged before surgery with a minimum for stage II patients that averaged only $32 \%$. In the present study, three patients with stage IIIB were understaged pre-operatively.

\section{Pulmonary perfusion and lung cancer}

The mechanisms of a reduction in perfusion of a lung or a portion of a lung with a cancer is still poorly understood but has been repeatedly reported to be one of the main features of lung cancer [19]. Typically, the defect in perfusion appears to involve a much larger portion of the lung than might be expected from the local extension of the tumour [8]. Indeed, in many patients, blood flow can be diverted from one lobe or even from an entire lung, whereas the tumour is limited in size and does not compress vascular elements [9]. Although an increased perfusion of the lung with the cancer has been reported, such a pattern of response appears to be relatively rare [19] and was not observed in the present study. During exercise, the increase in cardiac output, which is proportional to the rise in pulmonary gas exchange, can be perfectly accommodated by the pulmonary vascular bed without increasing the pressure in the pulmonary arteries due 
to the recruitment of the pulmonary bed. The present results suggest that the regions of the lung excluded by the tumour in terms of perfusion appear to lose the capability of adequately recruiting the pulmonary vascular bed when blood flow increases. The redistribution of the cardiac output towards the healthy portion of the lungs was indeed affected little when cardiac output increased. According to the present data, this observation may not be correct in the T3-T4 patients whose PBF redistribution appears to be more dependent on the level of pulmonary gas exchange and cardiac output than in the patients with a reduced local extent of the primary tumour. This difference did not reach significance however.

\section{Clinical relevance}

Can the present observation influence the traditional strategy for the treatment of lung cancer? The decision to operate on a patient with bronchogenic carcinoma is dictated by a combination of different factors, including the type of tumour, its local and systemic spread, the existence of general risk factors and the degree of pulmonary-function impairment $[1,5]$. The latter has been a subject of particular attention since the severity of lung dysfunction is closely related to postoperative morbidity and mortality [11]. In patients with a degraded pulmonary function, but without exclusion criteria, such as severe hypercapnia, exercise limitation or dramatic reduction in FEV1, one of the more traditional approaches comprises of predicting the effects of lung resection on the residual gas-exchange capacity of the respiratory system by estimating the postoperative FEV1, DL,CO or maximal $\mathrm{O}_{2}$ uptake. This is achieved by simply multiplying the proportion of the perfusion or ventilation of the remaining lung tissues by pre-operative FEV1 or DL,CO [7-10]. The predictability of such split-function tests has been extensively studied for FEV1. However, most of the original papers drew their conclusions from a rather limited number of subjects (from 19 subjects for KRISTERSSON [10], 23 and 13 for OLSEN and coworkers [6 and 7, respectively], from nine to 23 for Wernly et al. [8], 20 for BRIA et al. [23], 14 for Julius et al. [24] and 25 for Bolliger et al. [11]). In a more recent study, GIORDANo et al. [25] reported, in a group of 41 patients, an imprecision of $18.1 \%$ and an inaccuracy of $22.9 \%$ for FEV1,ppo. Nevertheless, this approach is still the most robust way of assessing postoperative functionality of the lung when combined with other parameters such as maximal $V^{\prime} \mathrm{O}_{2}$ and $D$ L, CO [5].

However, such a prediction may lose its relevance if, for example, the perfusion of the resected lung tissue is actually greater during exercise than at rest; in other words, the remaining lung would have to accommodate a larger blood flow and volume than expected from a standard resting scanning test. The present results suggest that this is not the case in most patients. Such a finding implies that all the predictive parameters, based on resting split-function tests, such as predictive FEV1 (FEV1,ppo), DL, CO or maximal $\mathrm{O}_{2}$ uptake [5], are independent of the level of PBF in the majority of patients. In two patients, however, the large redistribution of $\mathrm{PBF}$ towards the healthy lung during exercise led to an underestimation of any predictive parameters based on PBF redistribution. It is worth noting that the patients whose surgery would have been denied or discussed had the greatest change in blood-flow redistribution.

To conclude, the resting scanning gives a reasonable estimation of the redistribution of cardiac output when pulmonary blood flow increases in most but not all patients. Although the benefits of the present findings for evaluating lung-resection candidates remain to be demonstrated, the variability of pulmonary blood flow redistribution, when cardiac output changes, must be acknowledged as a limiting factor in predicting postoperative function. The resting scan, however, appears to be a valuable method in most patients requiring surgery.

\section{References}

1. Schirren J, Krysa S, Trainer S, Drings P, VogtMoykopf I. Surgical treatment and results. Carcinoma of the lung. Eur Respir Mon 1995; 1: 212-240.

2. Olsen GN, Weiman DS, Bolton JW, Gass GD, McLain WC, Schoonover GA. Submaximal invasive exercise testing and quantitative lung scanning in the evaluation for tolerance of lung resection. Chest 1989; 95: 267-273

3. Fee HJ, Holmes EC, Gewirtz HS, Ramming KP, Alexander JM. Role of pulmonary vascular resistance measurements in preoperative evaluation of candidates for pulmonary resection. $J$ Thorac Cardiovasc Surg 1978; 75: 519-524.

4. Ferguson MK, Reeder LB, Mick R. Optimizing selection of patients for major lung resection. J Thorac Cardiovasc Surg 1995; 109: 275-283.

5. Bolliger CT, Perruchoud AP. Functional evaluation of the lung resection candidates. Eur Respir J 1998; 11: 198-212.

6. Olsen GN, Block AJ, Swenson EW, Castle JR, Wynne JW. Pulmonary function evaluation of the lung resection candidates: a prospective study. Am Rev Respir Dis 1975; 111: 379-387.

7. Olsen GN, Block AJ, Tobias JA. Prediction of postpneumonectomy pulmonary function using quantitative macroaggregate lung scanning. Chest 1974; 66: 13-16.

8. Wernly JA, Demeester TR, Kirchner PT, Myerowitz PD, Oxford DE, Golomb HM. Clinical value of quantitative ventilation-perfusion lung scans in the surgical management of bronchogenic carcinoma. J Thorac Cardiovasc Surg 1980; 80: 535-543.

9. Garnett ES, Goddard BA, Machell ES, MacLeod WM. Quantitated scintillation scanning for the measurement of lung perfusion. Thorax 1969; 24: 372-373.

10. Kristersson S. Preoperative evaluation of differential lung function (133 Jod-radiospirometry) in bronchial carcinoma. Scand J Respir Dis 1974; 85: 110-117.

11. Bolliger CT, Wyser C, Roser H, Soler M, Perruchoud AP. Lung scanning and exercise testing for the prediction of postoperative performance in lung 
resection candidates at increased risk for complications. Chest 1995; 108: 341-348.

12. Bolliger CT, Jordan $\mathrm{P}$, Soler $\mathrm{M}$, et al. Exercise capacity as a predictor of postoperative complications in lung resection candidates. Am J Respir Crit Care Med 1995; 151: 1472-1480.

13. Walsh GL, Morice RC, Putman JB, et al. Resection of lung cancer is justified in high-risk patients selected by exercise oxygen consumption. Ann Thorac Surg 1994; 58: 704-711.

14. Bechard D, Wetstein L. Assessment of exercise oxygen consumption as preoperative criterion for lung resection. Ann Thorac Surg 1987; 44: 344499.

15. Smith TP, Kinasewitz GT, Tucker WY, Spillers WP, George RB. Exercise capacity as a predictor of postthoracotomy morbidity. Am Rev Respir Dis 1984; 129 : 730-734.

16. Haouzi P, Hirsch JJ, Marchal F, Huszczuk A. Ventilatory and gas exchange response during walking in severe peripheral vascular disease. Respir Physiol 1997; 107: 181-190.

17. Mountain CF. A new international staging system for lung cancer. Chest 1986; 89: Suppl. 4, 225S-233S.

18. Quanjer PH. Standardized lung function testing: Report working party "Standardization of Lung Function Tests". Bull Eur Physiopathol Respir 1983; 19: $1-95$.
19. Fraser HS, Macleod WM, Garnett ES, Goddard BA. Lung scanning in the preoperative assessment of carcinoma of the bronchus. Am Rev Respir Dis 1970; 101: 349-358.

20. Van Houtte P, Mornex F. Radiotherapy of non-smallcell and small-cell lung cancer. Carcinoma of the lung. Eur Respir Mon 1995; 1: 241-268.

21. Thatcher N, Ranson M, Anderson H. Chemotherapy in non-small-cell lung cancer. Carcinoma of the lung. Eur Respir Mon 1995; 1: 269-305.

22. Bülzebruck H, Bopp R, Drings $\mathrm{P}$, et al. New aspects in the staging of lung cancer: prospective validation of the International Union Against Cancer TNM classification. Cancer 1992; 70: 1102-1110.

23. Bria W, Kanarek D, Kazemi H. Prediction of post operative pulmonary function following thoracic operations. J Thorac Cardiovasc Surg 1983; 86: 186-192.

24. Julius AJ, De Jong D, van Deutekom H, Heidendal GA, Den Otter G, Kester AD. The value of ${ }^{99 \mathrm{~m}} \mathrm{Tc}$ macroaggregated albumin lung perfusion scanning in the prediction of postpneumonectomy function and pulmonary artery pressure. Scand $J$ Thorac Cardiovasc Surg 1987; 21: 81-85.

25. Giordano A, Calcagni ML, Meduri G, Valente S, Galli G. Perfusion lung scintigraphy for the prediction of postlobectomy residual pulmonary function. Chest 1997; 111: 1542-1547. 